\title{
HLA and Mooren's ulceration
}

Craig J Taylor, Sheila I Smith, Catherine H Morgan, Susan F Stephenson, Tim Key, M Srinivasan, Emmett Cunningham Jr, Peter G Watson

\begin{abstract}
Background-Mooren's ulcer is a progressive intractable destructive peripheral ulceration of the cornea, probably of autoimmune aetiology. The disease is rare in the northern hemisphere but is more common in southern and central Africa and the Indian subcontinent. Although rare, its predominance in certain racial groups and their second generation migrants worldwide indicates a genetic as well as a geographic predisposition. The highly polymorphic human leucocyte antigens (HLA) confer genetic susceptibility to several autoimmune disorders. Therefore, a possible link between Mooren's ulcer and HLA type was investigated.

Methods-Patients (n=22) with noninfective destructive peripheral corneal inflammatory disease were recruited worldwide. Differential diagnosis confirmed Mooren's ulceration in 12 cases. HLA typing (HLA-A, B, C, DRB, DQB) was performed by serology and PCR using sequence specific primers. The patients came from varied ethnic backgrounds and their HLA typing results were compared with published data from ethnically matched control populations.
\end{abstract}

Results-Of the 12 patients with Mooren's ulcer, 10 (83\%) were HLA-DR17(3) positive (including all nine patients of Asian, Indonesian, and black African origin), and $10(83 \%)$ were HLA-DQ2 positive. The frequency of HLA-DR17(3) and DQ2 was higher in the Mooren's ulcer group compared to published data from ethnically matched control populations, where the expected antigen frequencies range between $5 \%$ and $40 \%$.

Conclusion-These results suggest a possible association between HLA-DR17(3) and/or DQ2 and susceptibility to Mooren's ulcer.

(Br F Ophthalmol 2000;84:72-75)

Mooren's ulceration is a chronic stromal ulceration of the cornea with a characteristically undermined border. ${ }^{12}$ The ulcer starts peripherally and progresses slowly and unrelentingly accompanied by much pain, until the entire cornea is involved. Perforation is rare and usually results from minor trauma to a very thin cornea. This destructive blinding condition is rare in the northern hemisphere but is more commonly found in southern African, Indian, and Far Eastern populations. Although this is usually a disease of the elderly the most aggressive clinical manifestation starts at a younger age (20-40 years) and is often ultimately bilateral, leading to perforation and blindness. ${ }^{3}$

Mooren's ulcer has a characteristic clinical appearance which distinguishes it from other types of peripheral corneal ulceration. Mooren's ulcers start with a crescent-shaped peripheral corneal ulcer which progresses centrally preceded by infiltration and thickening of the adjacent cornea. New vessels come to the advancing edge of the ulcer but not beyond. The destruction of the cornea affects stromal corneal tissue only, leaving the epithelium and endothelium largely unaffected. There is no involvement of the adjacent sclera and Mooren's ulceration is not associated with any detectable systemic disease. ${ }^{3}$

Mooren's ulceration is thought have an autoimmune aetiology. ${ }^{4}$ Support for this has come from recent work by Gottsch et al who have identified antibodies in Mooren's ulcer patients with specificity for a $7 \mathrm{kDa}$ antigen (calgranulin $\mathrm{C}, \mathrm{COAg}$ ) expressed uniquely on the cornea stromal tissue. ${ }^{5}$ Calgranulin $\mathrm{C}$ is also found in circulating polymorphonuclear leucocytes. A similar antigen has been identified from bovine corneal epithelium and corneal epithelium of patients with Mooren's ulceration, but is absent in healthy control patients. ${ }^{6-8}$ Epidemiological studies have indicated trauma, previous cataract surgery, bacterial and helminth infection, but not viral infection, to be contributory risk factors to disease development. ${ }^{9}$

Although the clinical appearance of Mooren's ulceration is identical in affected populations, the progression and outcome of the disease is very different. ${ }^{3}$ Furthermore, the disease has been found to affect these populations whether they are indigenous or living abroad. Its occurrence in second generation migrants worldwide indicates a possible genetic as well as geographic predisposition. It is possible, therefore, that although the triggers and factors that allow the amplification of the immune response are different in the various populations, the characteristic clinical appearance of Mooren's ulceration will occur predominantly in patients with a common genetic predisposition.

The highly polymorphic human leucocyte antigens (HLA) are pivotal to antigen recognition as they govern the repertoire of both intracellular and extracellular self and foreign peptides which are presented to immunocompetent $\mathrm{T}$ lymphocytes. HLA associated aberrant $T$ cell activation against tissue specific self antigens has been described in several autoimmune diseases such as coeliac disease, Graves' disease, rheumatoid arthritis, insulin dependent diabetes, and multiple sclerosis. ${ }^{10}$ We have therefore initiated a study to identify 
Table 1 Patient demographics and diagnoses

\begin{tabular}{|c|c|c|c|c|c|c|c|}
\hline No & Source & Ethnic group & Age & Sex & Diagnosis & Other factors & Systemic diagnosis \\
\hline 1 & Sweden & European white & 65 & $\mathrm{~F}$ & Unilateral Mooren's ulcer & None & None \\
\hline 2 & $\mathrm{UK}$ & European white & 71 & M & Unilateral Mooren's ulcer & None & None \\
\hline 3 & South Africa & Black African & 15 & M & Unilateral Mooren's ulcer & Bilharzia & None \\
\hline 4 & Poland & European white & 60 & $\mathrm{~F}$ & Bilateral aggressive Mooren's ulcer & None & None \\
\hline 5 & India & Asian & 44 & $\mathrm{~F}$ & Unilateral Mooren’s ulcer & None & None \\
\hline 6 & India & Asian & 50 & M & Unilateral Mooren's ulcer & $\begin{array}{l}\text { Helminthic infection, } \\
\text { minor trauma }\end{array}$ & None \\
\hline 7 & India & Asian & 40 & M & Bilateral aggressive Mooren's ulcer & None & None \\
\hline 8 & South Africa & Black African & 28 & M & Bilateral aggressive Mooren's ulcer & None & None \\
\hline 9 & South Africa & Black African & 15 & $\mathrm{~F}$ & Unilateral Mooren’s ulcer & Bilharzia, Vernal & None \\
\hline 10 & South Africa & Black African & 13 & M & Unilateral Mooren's ulcer & Minor trauma & None \\
\hline 11 & Australia & Indonesian & 34 & $\mathrm{~F}$ & Unilateral Mooren's ulcer & None & $\begin{array}{l}\text { Insulin dependent } \\
\text { diabetes }\end{array}$ \\
\hline 12 & Holland & Asian & 45 & $\mathrm{~F}$ & Bilateral aggressive Mooren's Ulcer & None & None \\
\hline
\end{tabular}

HLA polymorphisms in patients with various types of corneal ulceration from as many different populations as possible, in order to identify candidate genes which may predispose to disease.

\section{Patients and methods}

PATIENTS

Mooren's ulceration is an extremely rare disease. One of us (PGW) has treated only 40 such patients in 35 years' experience in referral corneal clinics in the UK. However, with the help of many ophthalmic surgeons throughout the world, blood samples were collected for HLA typing from 22 patients with noninfectious peripheral destructive corneal inflammatory disease. Clinical descriptions and photographs enabled the diagnosis of Mooren's ulcer to be confirmed in 12 patients, of whom three were European white people, four black South Africans, four Asian Indians, and one Indonesian (Table 1). The remaining 10 patients with peripheral sclerokeratitis or destructive corneal disease of other types, were all of European white decent.

HLA TYPING

Blood samples $(10 \mathrm{ml}$ volumes in trisodium citrate) were stored frozen $\left(-20^{\circ} \mathrm{C}\right)$ before shipping or despatched "fresh" to the tissue typing laboratory, depending on their country of origin. Freshly derived blood samples (containing viable lymphocytes) were HLA-A and $B$ typed by serology using local, national, and internationally exchanged HLA typing reagents. CD8 positive $\mathrm{T}$ lymphocytes were isolated using "Dynabeads HLA Class I" (Dynal, Oslo, Norway) according to the manufacturer's instructions. HLA typing was performed using the standard NIH lymphocyto- toxicity test followed by vital staining with acridine orange and ethidium bromide. ${ }^{11}$ HLA-C, DR, and DQ typing (and additionally HLA-A and B from frozen blood samples) was performed on genomic DNA using PCR-SSP (polymerase chain reaction using sequence specific primers) according to the methods of Bunce et al (HLA-A,-B,-C) ${ }^{12}$ and Olerup et al (HLA-DRB,-DQB). ${ }^{13-15}$

HLA phenotype frequency data of ethnically matched control populations was obtained from standard reference text and compared with the patient HLA typing results. ${ }^{16-19}$ Owing to the small numbers of patients of various ethnic origins, this was conducted as an observational study, without the use of statistical comparisons.

\section{Results}

No correlations with HLA-A, B, and C locus specificities were observed. The HLA class II typing results of Mooren's ulcer patients are shown in Table 2. An increased frequency of HLA-DR17(3), DRw52, and DQ2 was observed in the Mooren's ulcer group, with 10 of $12(83 \%)$ patients being HLA-DR17(3), including all nine patients from India, Indonesia, and South Africa. In addition, 10 of 12 (83\%) patients with Mooren's ulcer had HLA-DQ2. The HLA-DR17(3) antigen frequency in published population studies are $11 \%$ (range 4-19\%) in India, 10-20\% in black South Africans, and $23 \%$ in northern European white people (Table 3). ${ }^{16-19}$ For HLA-DQ2, the published antigen frequencies are 39\% (range $36-45 \%$ ) in India, $17-19 \%$ in black South Africans and $33 \%$ in northern European white people (Table 3). ${ }^{16-19}$

In addition, all 12 patients with Mooren's ulcer were HLA-DRw52 positive. However,

Table 2 HLA class II typing results

\begin{tabular}{|c|c|c|c|c|c|c|c|c|}
\hline No & Source & Ethnic group & $D R$ & $D R$ & $D R w$ & $D R w$ & $D Q$ & $D Q$ \\
\hline 1 & Sweden & European white & 7 & $13(6)$ & 52 & 53 & 2 & $6(1)$ \\
\hline 2 & UK & European white & 1 & 17 (3) & 52 & & 2 & $5(1)$ \\
\hline 3 & South Africa & Black African & $13(6)$ & 17 (3) & 52 & & 2 & $6(1)$ \\
\hline 4 & Poland & European white & 1 & $11(5)$ & 52 & & $5(1)$ & 7 (3) \\
\hline 5 & India & Asian & 7 & $17(3)$ & 52 & & 2 & 9 (3) \\
\hline 6 & India & Asian & $14(6)$ & $17(3)$ & 52 & & 2 & $5(1)$ \\
\hline 7 & India & Asian & 7 & $17(3)$ & 52 & 53 & 2 & \\
\hline 8 & South Africa & Black African & 8 & 17 (3) & 52 & & 7 (3) & \\
\hline 9 & South Africa & Black African & 1 & $17(3)$ & 52 & & 2 & $5(1)$ \\
\hline 10 & South Africa & Black African & $12(5)$ & $17(3)$ & 52 & & 2 & $5(1)$ \\
\hline 11 & Australia & Indonesian & $15(2)$ & 17 (3) & 52 & 51 & 2 & $5(1)$ \\
\hline 12 & Holland $\star$ & Asian & 7 & $3 \dagger$ & 52 & 53 & 2 & \\
\hline
\end{tabular}

* Serologically determined HLA type and clinical details kindly supplied by Dr Volker-Deiben.

†HLA-DR17(3) is a subtype of the serologically defined HLA-DR3 specificity. 
Table 3 Frequency of HLA-DR17(3) and DQ2 in Mooren's ulcer patients and control populations

\begin{tabular}{|c|c|c|c|c|c|}
\hline \multirow[b]{2}{*}{$H L A$} & \multirow{2}{*}{$\begin{array}{l}\text { All } \\
M U \text { patients }\end{array}$} & \multirow{2}{*}{$\begin{array}{l}\text { Non-white } \\
M U \text { patients }\end{array}$} & \multicolumn{3}{|c|}{ Population frequencies } \\
\hline & & & White & Indian & African \\
\hline DR17(3) & $10 / 12(83 \%)$ & $9 / 9(100 \%)$ & $23 \%$ & $11 \%(4-19 \%)$ & $10-20 \%$ \\
\hline DQ2 & $10 / 12(83 \%)$ & $8 / 9(89 \%)$ & $33 \%$ & $39 \%(36-45 \%)$ & $17-19 \%$ \\
\hline
\end{tabular}

unlike DR17(3) and -DQ2, DRw52 is found frequently in most ethnic groups $(80 \%)$, and this observation may therefore be the result of chance alone. Only one of the $10(10 \%)$ patients with other forms of destructive sclerokeratitis was HLA-DR17(3) and three of the $10(30 \%)$ were HLA-DQ2 which is no different from the expected antigen frequencies observed in control population studies.

\section{Discussion}

Mooren's ulcer is a rare, painful condition which initially affects the stroma of the peripheral cornea. Untreated, and sometimes even if treated vigorously, the disease spreads inexorably to involve the whole of the stroma of the cornea but the endothelium and epithelium are almost always unaffected. The condition affects all races but is much more common in west, central, southern Africa, and southern India. ${ }^{9}$ It is also seen in these populations when they have migrated elsewhere. It is possible that the clinical course is determined by different triggers, the frequency of ocular trauma and infection together with a differing immune response resulting from age or intercurrent infection in susceptible individuals. This study was instigated to discover whether there are candidate genes which might predispose to Mooren's ulceration.

In view of the extreme rarity of this disease, assistance was sought from corneal surgeons worldwide to identify patients with Mooren's ulcer and similar non-infectious corneal destructive disease who are currently under treatment. We were able to obtain blood samples from 22 such patients. Twelve of these patients were confirmed to have Mooren's ulcer. Despite the small sample size and heterogeneity of ethnic background, of these 12 patients, 10 (83\%) had HLA-DR17(3) and/or DQ2 which included all nine patients of Asian, Indonesian, and black African origin. This antigen frequency was notably higher than even the highest frequency reported in ethnically matched control population studies. Furthermore, this high frequency occurring despite the wide range of ethnic origins indicates that HLA may constitute a susceptibility gene this disease.

In addition to a genetic disposition there must be other factors which would trigger the disease and allow it to be perpetuated, particularly in India and Africa. Recently, Gottsch et al have shown that serum from patients with Mooren's ulcer contain antibodies to a cornea associated antigen, COAg. ${ }^{5-8}$ This antigen has now been found to be identical to calgranulin $\mathrm{C}$ which only occurs in the corneal stroma and in neutrophils. Receptors for calgranulin $\mathrm{C}$ are also known to occur on the surface of certain helminths.
It is possible, therefore, that wherever the disease is found there is a sensitisation phase after which, if the correct conditions arise, the specific corneal changes characteristic of Mooren's ulceration can be induced. Sensitisation to calgranulin $\mathrm{C}$ could occur either acutely as a result of corneal infection or trauma, in which corneal tissue breakdown occurs resulting in the expression of normally cryptic tissue specific corneal antigens, or gradually during the normal slow turnover of tissue throughout the years. In addition, sensitisation to calgranulin C may occur subsequent to helminth infestation. In either case antigen presenting cells (APC) normally present at the limbus would present these "self" or "cross reactive" antigens in the form of short peptides bound to HLA class II molecules. Sensitisation would only occur in susceptible individuals with the appropriate HLA genotypes as only a limited repertoire of peptides can associate with each HLA molecule. Under these circumstances antigen/MHC specific $\mathrm{T}$ cells will be primed.

At a later date if one or both corneas are injured mechanically, surgically, or as a result of infection there would be macrophage infiltration of the cornea, and IFNg induced upregulation of cellular HLA expression. ${ }^{4}$ This would be particularly intense if there is a high circulating level of calgranulin C associated with a concomitant helminth infestation and its accompanying neutrophilia. An autoimmune response would then occur as a result of the presentation to and the response from previously primed effector T cells. Such a course of events would explain the worldwide genetic and geographic distribution, the rarity, and the absolute corneal stromal tissue specificity of this autoimmune condition.

The results of this study indicate HLADR17(3) and/or DQ2 as being the candidate restriction molecule(s) for presentation of the calgranulin C peptide to antigen specific/MHC restricted $\mathrm{T}$ lymphocytes. However, owing to the extreme rarity of Mooren's ulcer, the number of patients in this study is small and the results are therefore tenuous. Further collaborative studies are required on a larger multiethnic patient cohort to verify this HLA association.

We wish to thank the following ophthalmic surgeons who have kindly supplied clinical details, photographs and blood samples from their patients; Dr H Volker-Dieben (Amsterdam, Netherlands), Mr SJ Morgan, (Sunderland, UK), Dr S Sacks, (Johannesburg, South Africa), Dr CA Eggink (Niimegen, Netherlands), Dr L Levitz (Pretoria, South Africa), Dr B Rajeev (Hyderabad, India), Dr G Pollock and Professor H Taylor (Melbourne, Australia), Dr A Kardaszewska (Lublin, Poland), Dr U Stenevi (Goteborg, Sweden), Dr J Gottsch (Baltimore, USA).

1 Bowman W. In: The parts concerned in the operation of the eye 1849; Case 12:112, cited by Nettleship E. Chronic serpiginous ulcer of the cornea (Mooren's ulcer). Trans Ophthalmol Soc UK 1902;22:103-44.

2 Mooren A. Ulcus rodens. Ophalmiatriche Beobachtungen. Berlin: Hirschwald A, 1867:107-10.

3 Watson PG. Management of Mooren's ulceration. Eye 1997;11:349-56.

4 Sangwan VS, Zafirakis P, Foster CS. Mooren's ulcer: current concepts in management. Indian $\mathcal{F}$ Ophthalmol 1997;45:7-17.

5 Gottsch JD, Liu SH, Minkovitz JB, et al. Autoimmunity to a cornea-associated stromal antigen in patients with Mooren's ulcer. Invest Ophthalmol Vis Sci 1995;36:1541-7.

6 Gottsch JD, Liu SH. Cloning and expression of human corGottsch JD, Liu SH. Cloning and expression of human cor-
neal calgranulin C (CO-Ag). Curr Eye Res 1998;17:870-4. 
7 Gottsch JD, Liu SH. Cloning and expression of bovine corneal antigen cDNA. Curr Eye Res 1997;16:1239-44. analysis of human and bovine corneal antigen (CO-Ag) cDNA: identificatio C. Trans Am Ophthalmol Soc 1997;95:111-25; discussion $126-9$

9 Zegans ME, Srinivasan M, McHugh T, et al. Mooren's ulcer in south India: serology and clinical risk factors. $\mathrm{Am} \mathcal{F} \mathrm{Oph}$ thalmol 1999;128:205-10.

10 Heard R. HLA and autoimmune disease. In: Lechler R, ed. HLA and disease. London: Academic Press, 1994:123-51.

11 Darke C, Dyer P. Clinical HLA typing by cytotoxicity. In Dyer P, Middleton D, eds. Histocompatibility testing: a practical approach. Oxford: Oxford University Press, 1993:5180.

12 Bunce M, O'Neill CM, Barnardo MC, et al. Phototyping: comprehensive DNA typing for HLA-A, B, C, DRB1,
DRB3, DRB4, DRB5 and DOB1 by PCR with 144 primer mixes utilizing sequence-specific primers (PCR-SSP). Tissue Antigens 1995;46:355-67.

13 Olerup O, Zetterquist H. HLA-DR typing by PCR amplification with sequence-specific primers (PCR-SSP) in 2 hours: an alternative to serological DR typing in clinical practice including donor-recipient matching in cadaveric transplantation. Tissue Antigens 1992;39:225-35.
14 Olerup O, Zetterguist H. DR "low-resolution" PCR-SSP typing - a correction and an up-date. Tissue Antigens 1993; 41:55-6.

15 Olerup O, Aldener A, Fogdell A. HLA-DQB1 and -DQA1 typing by PCR amplification with sequence-specific primers (PCR-SSP) in 2 hours. Tissue Antigens 1993;41: 119-34.

16 Clayton J, Lonjou C, Whittle D. Allele and haplotype frequencies for HLA loci in various ethnic groups. In: Charron D, ed. Genetic diversity of HLA. Functional and medical implication. Volume 1. Workshop. Sevres, France: EDK, Medical and Scientific International, 665-820.

17 Gjertson DW, Lee SH. HLA-A/B and DRB1/DQB1 allele level haplotype frequencies. In: Gjertson DW, Terasaki PI, eds. HLA 1998. Kansas, USA: American Society for Histocompatibility and Immunogenetics, 1998:365-450.

18 Geer L, Terasaki PI, Gjertson DW. Gene frequencies and world maps of their distributions. In: Gjertson DW, Terasaki PI, eds. HLA 1998. Kansas, USA: American Society for Histocompatibility and Immunogenetics, 327-363.

19 Dyer P, Middleton D, eds. HLA-A, -B, -C, -DR, and -DQ allele frequencies in different ethnic groups. In: Histocompatibility testing: a practical approach. Oxford: Oxford University Press, 1993:260-8. 